\title{
Prescribing for Women with Breast Cancer in Their Survivorship Phase for Menopausal Symptoms
}

\author{
Nuttan Tanna ${ }^{1}$ (1), Naim Kadoglou² (1), Luca Fusi ${ }^{1}$ \\ ${ }^{1}$ Women's Services, Northwick Park Hospital, London North West University Healthcare NHS Trust, Watford Road, Harrow, Middlesex, UK \\ ${ }^{2}$ Breast Unit, Northwick Park Hospital, London North West University Healthcare NHS Trust, Watford Road, Harrow, Middlesex, UK
}

Cite this article as: Tanna N, Kadoglou N, Fusi L. Prescribing for Women with Breast Cancer in Their Survivorship Phase for Menopausal Symptoms. Eur J Breast Health 2020; 16(2): 155-157.

Dear Editor,

In developed countries breast cancer survival is improving. In the UK the rate of survival has doubled in the last 40 years. In the 1970 s, four in ten women diagnosed with breast cancer survived their disease beyond ten years, now it's around eight in ten (1).

There were 55,000 new cases of invasive breast cancer diagnosed in the UK between 2014-2016. With around 8,000 new breast carcinoma in situ cases identified every year, this equates to 22 new cases being recorded every day (2). With treatment these women can be advised that they have an estimated $78 \%$ survival rate of ten or more years (2). Around two-thirds (65\%) of women diagnosed with breast cancer in England and Wales survive their disease for twenty years or more (1). It is noteworthy that the age range 50-69 years is when the chances of breast cancer survival are highest (Figure 1).

\section{Breast Cancer and Menopause Management}

Women with breast cancer depending on their diagnostic stage and prognosis may be advised to undergo treatments which include chemotherapy, radiotherapy and adjuvant hormone therapy (Figure 2) (3, 4). Breast cancer treatments per se can induce the menopause, which can be accompanied by debilitating vasomotor and emotional symptoms. Generally, the climacteric, the period of life when fertility and sexual activity are in decline and which depicts the end of the reproductive phase in women, ranges from age 45 to 55 . Natural menopause occurs around 51 years of age (5). Many women will go through an earlier menopause with breast cancer therapy (3) or may be at the age of natural menopause and then face additional debilitating symptoms with breast cancer treatment.

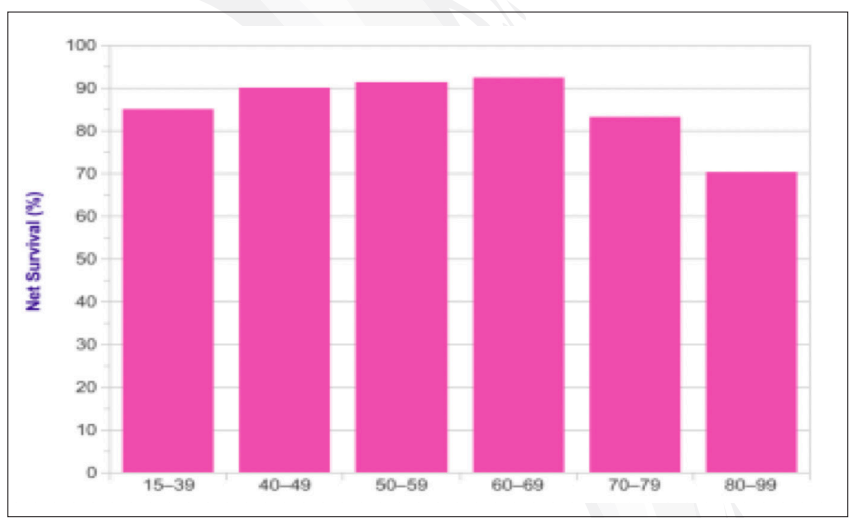

Figure 1. Breast cancer (C50): 2009-2013. Five year net survival by age, Women, England (2)

Acknowledgement Cancer Research UK

\section{The Breast Cancer and Menopause Service (BCMS)}

In this paper we present the treatment and prescribing guidance which has been compiled (Appendix 1), working in close liaison and jointly by specialist multi-disciplinary teams, within our hospital. The treatment and prescribing guidance provide the evidence base and consensus for best practice and care for patients seen within the breast cancer and menopause service.

The BCMS service was established in 2007 after identifying the need and following a pilot phase $(6,7)$. The service accepts referrals for women with high risk for breast cancer or those with breast cancer who have undergone treatment, who are now in their survivorship phase, and suffering with menopausal symptoms. The joint BCMS service has been established using a clinical governance approach (6-14), and operates at a general district hospital which is a university accredited healthcare Trust in North West London. Patient views are important 
and can assist with successful service development. In line with this, research has been undertaken with various breast cancer patient cohorts including Caucasian $(14,15)$, Asian (16) and women with breast cancer who have been seen within the BCMS service and those who have not (Table 1) (14). Figure 3 shows the symptom assessment chart that all patients seen within the general menopause and the BCMS service complete at each clinic visit. The symptom assessment chart is used to help with objective assessment of symptom relief in between consultations.

The approach (6-8) taken to ensure a high standard of patient care delivery has involved joint collaborative working between the Trust breast and menopause services and included input from the genetics counselling team, the development of an appropriate history taking

\begin{tabular}{|l|l|}
\hline \multicolumn{1}{|c|}{$\begin{array}{l}\text { Cyclophosphamide (alkylating agents) } \\
\text { Anthracycline regimens (FEC) } \\
\text { Taxanes - docetaxel; paclitaxel }\end{array}$} & $\begin{array}{l}\text { Aromatase Inhibitors } \\
\text {-anastrozole; letrozole; exemestane } \\
\text { Selective oestrogen receptor modulators } \\
\text {-tamoxifen; [raloxifene]; toremifene) } \\
\text { Oestrogen receptor downregulators } \\
\text { - fulvestrant }\end{array}$ \\
\hline $\begin{array}{l}\text { Ovarian ablation } \\
\text { Prostap (Leuprorelin) }\end{array}$ & $\begin{array}{l}\text { Targeted therapies } \\
\text { Surgery (BSO) }\end{array}$ \\
\hline Radiotherapy & $\begin{array}{l}\text { Herceptin (trastuzumab) } \\
\text { Tykerb (lapatinib) } \\
\text { Pvastin (bevacizumab) }\end{array}$ \\
\hline
\end{tabular}

Figure 2. Treatments inducing menopause (temporary or permanent) and those causing menopausal symptoms proforma by the BCMS service multi-disciplinary team which is also utilised to support teaching and training for junior medical staff, and audit and research activity to drive evidence based service development (7, 8, 13-15), and as stated above the writing of the BCMS prescribing guidelines. These were first drafted in 2009 after an extensive literature search, updated subsequently in 2012 and 2015 and with ratification by the Trust Drugs and Therapeutics Committee (DTC) at each stage.

These guidelines have undergone evidence-based review and have been updated using collaborative consensus methodology. We present the current updated document of the BCMS guidelines in Appendix 1 and invite comments and input from the readership to further inform safe, holistic and empathetic delivery of care to women with high risk for breast cancer or for those with breast cancer in their survivorship phase.

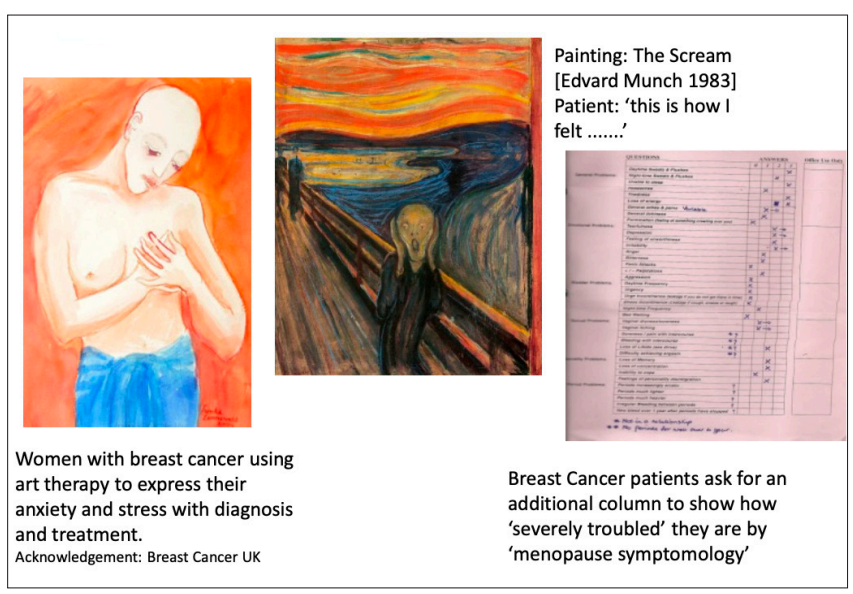

Figure 3. Breast cancer survivorship

Table 1. Demographic data for focus group participants - UK Caucasian and Asian women attending support group. Breast Cancer Patient Stories Project (15)

\begin{tabular}{|c|c|c|c|}
\hline & $\begin{array}{l}\text { Caucasian } \\
\text { BC patient } \\
\text { group }\end{array}$ & $\begin{array}{l}\text { Asian } \\
\text { BC patient } \\
\text { group }\end{array}$ & Comments \\
\hline No. of women taking part in focus group & 13 & 7 & $\begin{array}{l}\text { All } 13 \text { of } 13 \text { Caucasian, but only } 7 \text { of } 25 \text { Asian } \\
\text { women attending on the evening took part in the } \\
\text { focus group }\end{array}$ \\
\hline Avarage Age (range) & $\begin{array}{l}62.4 \text { years } \\
(49-91)\end{array}$ & $\begin{array}{l}55.4 \\
(49-61)\end{array}$ & $\begin{array}{l}\text { Older Asian women who could not speak English } \\
\text { decided not to take part. }\end{array}$ \\
\hline No. with first $B C /$ No. with $B C$ recurrence & $12 / 1$ * & $7 / 0$ & $\begin{array}{l}\text { Patient with BC recurrence*, recently diagnosed, } \\
\text { felt her strong faith would help her get through } \\
\text { this phase in life }\end{array}$ \\
\hline Partner/Carer attending & $2 / 1 * *$ & $0 / 1 * *$ & Both carers** were sisters of BC patients \\
\hline Time since first diagnosis & $\begin{array}{l}6 \text { years } \\
\text { (range } \\
9 \text { month- } \\
14 \text { years) }\end{array}$ & $\begin{array}{l}1.9 \text { years } \\
\text { (range } 1.2- \\
4.3 \text { years) }\end{array}$ & $\begin{array}{l}\text { The patient with BC recurrence* had had her first } \\
\text { BC } 5 \text { years before }\end{array}$ \\
\hline $\begin{array}{l}\text { Menopausal stage at time of BC diagnosis: } \\
\text { Postmenopausal (last normal menstrual } \\
\text { period } 12 \text { months before) }\end{array}$ & 7 & 7 & $\begin{array}{l}\text { 1. BC patients were not sure if they had } \\
\text { menopausal symptoms or whether this was due to } \\
\text { their } B C \text { condition/BC treatment. }\end{array}$ \\
\hline $\begin{array}{l}\text { Perimenopausal (still having some } \\
\text { menstrual periods) }\end{array}$ & 3 & 0 & $\begin{array}{l}\text { 2. Asian women complained of erratic and heavy } \\
\text { bleeds as the most common problem at the time of }\end{array}$ \\
\hline Premenopausal (regular menstrual periods) & 3 & 0 & $\begin{array}{l}\text { their menopause. } \\
\text { 3. Self medicating but safety? }\end{array}$ \\
\hline
\end{tabular}


Peer-review: Externally peer-reviewed.

Author Contributions: Concept - N.T., N.K.; Design - N.T.; Supervision - N.K., L.F.; Materials - BCMS Prescribing Guidelines, London North West University Healthcare NHS Trust, September 2019; Literature Search - N.T.; Writing Manuscript - N.T.; Critical Review - N.K., L.F.

Acknowledgements: Miss Joan Pitkin, Consultant Gynaecologist and Mr Robert Reichert, Breast Consultant, Joint Leads for the BCMS service 2007- 2018.

Conflict of Interest: The authors have no conflicts of interest to declare.

Financial Disclosure: The guidance supports patient care delivery by a UK based National Health Service. The guidance has been compiled in line with National Institute for Health and Care Excellence, Scottish Intercollegiate Guidelines Network and UK Department of Health recommendations. For products mentioned in the guidelines, please refer to the UK Summary of Product Characteristics.

\section{References}

1. Cancer Research UK. https://www.cancerresearchuk.org/health-professional/cancer-statistics/statistics-by-cancer-type/breast-cancer\#headingThree. Accessed August 2019.

2. Cancer Research UK. https://www.cancerresearchuk.org/health-professional/cancer-statistics/statistics-by-cancer-type/breast-cancer. Accessed August 2019.

3. NICE guidelines CG101. Early and locally advanced breast cancer: diagnosis and management. Published July 2018. https://www.nice. org.uk/guidance/ng101/chapter/Finding-more-information-and-resources

4. NICE guidelines CG164. Familial breast cancer: classification, care and managing breast cancer and related risks in people with a family history of breast cancer. Published June 2013. Last updated March 2017. https:// www.nice.org.uk/guidance/cg164
5. NICE guidelines [NG23]. Menopause: diagnosis and management. Published November 2015. https://www.nice.org.uk/guidance/NG23

6. Tanna N, Woyka J, Abernethy K, Reichert R, Pitkin J. A joint specialist breast cancer and menopause symptoms (BCMS) clinic: Service development using a clinical governance approach. Eur J Surg Oncol 2009; 35: 1242. [CrossRef]

7. Tanna N, Buijs H, Longmate M, Pitkin J. Specialist Menopause Care for Breast Cancer Survivors. 6th Amsterdam Menopause \& Womens Health Symposium 2010; 120-121.

8. Woyka J, Pitkin J, Tanna N, Abernethy K. Establishing a dedicated menopause service for women with breast cancer or at high risk from breast cancer. Maturitas 2009; 63: S54. [CrossRef]

9. Tanna N, Pop A, Pitkin J. Prescribing of non-hormonal therapies within a joint specialist breast cancer and menopause symptoms (BCMS) clinic. Maturitas 2009; 63: S53. [CrossRef]

10. Pop A, Tanna N, Pitkin J. Breast cancer patient case study - prescribing of gabapentin for vasomotor symptom control and supporting patient compliance / concordance. Maturitas 2009; 63: S53. [CrossRef]

11. Woyka J, Tanna N, Abernethy K, Reichert R, Pitkin J. A menopause service for women with breast cancer or at high risk from breast cancer. Eur J Surg Oncol 2009; 35(: 1226-1227. [CrossRef]

12. Tanna N, Woyka J, Abernethy K, Reichert R, Pitkin J. A joint specialist breast cancer and menopause symptoms (BSMS) clinic: Service development using a clinical governance approach. 6th Amsterdam Menopause and Women's Health Symposium 2010, 119.

13. Tanna N, Batten C, Pitkin J. Audit of breast cancer patients on Aromatase Inhibitors with baseline DEXA scans. Osteoporosis Int 2010; 21: S481.

14. Tanna N, Buijs H, Pitkin J. Exploring the breast cancer patient journey: do breast cancer survivors need menopause management support? Menopause Int 2011; 17: 126-130. [CrossRef]

15. Tanna N, Buijs H, Pitkin J, Reichert R. Breast cancer patient stories project. Menopause Int 2012; 18: 128-133. (PMid:23081974) [CrossRef]

16. Tanna N, Shah D, Pitkin J. Support for menopause symptoms in Indian women with breast cancer. 9th European Congress on Menopause and Andropause. Maturitas 2012; 71(Suppl 1): S33. [CrossRef] 
Appendix 1. BCMS Prescribing Guidance July 2019

\section{The Joint Breast Cancer and Menopause Symptom Clinic Women Services, London North West University Healthcare NHS Trust.}

Consultant leads:

\section{Prescribing Guidelines}

Luca Fusi, Consultant Gynaecologist \& Menopause Services Lead, LNWUHT Naim Kadoglou, Consultant Breast Surgeon, Breast Unit, LNWUHT

Nuttan Tanna, Pharmacist Consultant, Women's Health \& Osteoporosis / Bone Health, LNWUHT \& Associate Director, The Northwick Park Menopause Clinical \& Research Unit

INDEX

\begin{tabular}{|l|l|l|}
\hline & \multicolumn{1}{|l|}{} & Page \\
\hline 1 & Introduction & 2 \\
\hline $\begin{array}{l}\text { Sreatment of hot flushes in women with breast cancer } \\
\text { Serotonin Noradrenaline Reuptake Inhibitors } \\
\text { Gabapentin } \\
\text { Clonidine } \\
\text { Progestogens } \\
* \text { Tamoxifen - Interaction with SSRI and SNRIs }\end{array}$ & 2 \\
\hline $\mathbf{2}$ & $\begin{array}{l}\text { Weaning off HRT in breast cancer patients } \\
\text { For patients to be prescribed Aromatase Inhibitors } \\
\text { For patients on HRT, with decision to wean them of when } \\
\text { diagnosed with breast cancer } \\
\text { Local vaginal estrogen therapy - for vaginal dryness and } \\
\text { dyspaereunia }\end{array}$ & 4 \\
\hline $\mathbf{3}$ & Alternative strategies & 6 \\
\hline $\mathbf{4}$ & BRCA1 and BRCA2 testing and induced menopause & $\mathbf{2}$ \\
\hline $\mathbf{5}$ & Bibliography & 12 \\
\hline $\mathbf{6}$ & $\begin{array}{l}\text { The LNWHT Menopause, Breast cancer and Genetic } \\
\text { Counselling Unit members }\end{array}$ & 15 \\
\hline
\end{tabular}



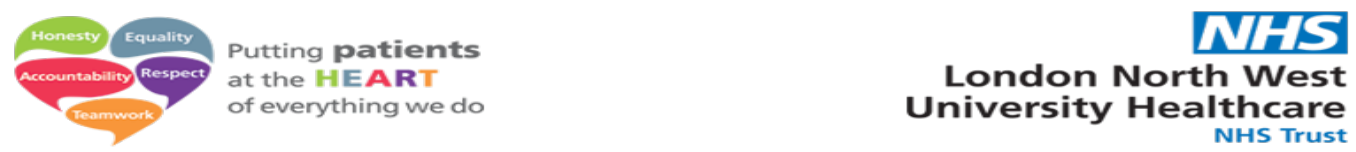

Introduction

NICE guidance NG23 (Nov 2015) suggest that women likely to go through the menopause as a result of medical or surgical treatment (including women with cancer, women at high risk of hormone sensitive cancer or having gynaecological surgery) should be offered

support and information about menopause and fertility before their treatment

referral to a healthcare professional with expertise in menopause.

Non hormonal prescribed options are generally not as effective for symptomatic treatment of menopause as HRT, but there may be individuals who may benefit (Drewe 2015; NICE NG23 2015; NICE NG101 2018). The evidence base or best practice for non hormonal options in breast cancer is presented below.

Menopausal women with or at high risk of breast cancer should be provided with information

on all available treatment options

that the SSRIs Paroxetine and Fluoxetine should not be offered to women with breast cancer who are taking Tamoxifen (anti-oestrogen) .

\section{Treatment of Hot Flushes in Women with Breast Cancer}

\section{Prescribing notes:}

1 SSRI: Selective serotonin reuptake inhibitors / Anti- Depressants

1. Best evidence for Paroxetine; off license use in UK (Nelson 2006)

2. Dose: 10mg daily (BNF app Jan 2019); higher doses not associated with improved control

3. Adverse affect on libido

4. Interaction with Tamoxifen (* see pg.4); do not prescribe concurrently for breast cancer patients on Tamoxifen

5. Other SSRIs evaluated in short duration trials for menopause symptom control include Fluoxetine and Citalopram with caution advised with concurrent prescribing with Tamoxifen ( ${ }^{\star}$ see pg. 4).

6. If a decision is made to prescribe SSRI with Tamoxifen (* see pg.4), then Citalopram may be the option to consider (Drewe 2015)

2 SNRIs: Serotonin noradrenaline reuptake inhibitors / Anti-Depressants.

1. Venlafaxine at doses $37.5 \mathrm{mg}-150 \mathrm{mg}$ Modified Release daily, off license use in UK.

2. Dose: $37.5 \mathrm{mg}$ daily for 1 week, then increase to $75 \mathrm{mg}$ daily (BNF app Jan 2019). 75 mg daily dose well tolerated; moderate GI or CNS symptoms in 10$20 \%$ users.

3. Counsel patients regarding nausea side effect; may be reduced by using long acting formulation as once daily dose with food, at night; the long acting formulation may also offer better control due to sustained systemic levels

4. Little or no interaction with Tamoxifen* - Note that Venlafaxine has weak potency for CYP450 2D6 genotype pathway interaction, so compared to SSRIs, is the preferred prescription for patients on Tamoxifen (Drewe 2015) 


\section{W/HS}

London North West University Healthcare
NHS Trust

5. May have an adverse effect on libido, but potentially lesser extent then SSRIs. One study with breast cancer patients reported improved libido with SSRIs / SNRIs.

6. Caution in patients with cardiovascular risks, eg. Cardiac ventricular arrhythmia; uncontrolled blood pressure; left ventricular dysfunction; recent $\mathrm{Ml}$; monitor cholesterol levels with long term treatment.

7. NB: Desvenlafaxine (active metabolite of Venlafaxine) evaluated for menopause symptom control. Not licensed in the UK; did not receive EMA approval 2017.

\section{Gabapentin: Gamma Aminobutyric Acid Analogue / Anti- epileptics.}

1. Researched in breast cancer patients on Tamoxifen, although short duration 12 week trials

2. Dose: $900 \mathrm{mg}$ daily, off license use (BNF app January 2019). Suggested initial regimen $300 \mathrm{mg}$ day $1,300 \mathrm{mg}$ twice daily on day 2, then $300 \mathrm{mg} 3$ times daily from day 3 .

3. Clinical experience suggests that slower titration of dose increase may help with improved patient compliance / concordance, eg. $300 \mathrm{mg}$ daily for 2 weeks, increase to $300 \mathrm{mg}$ bd for 2 weeks, then if tolerated increase to 300 $\mathrm{mg}$ tds. If daytime drowsiness is a major side effect, could try administration of total dose at night.

4. 2006 meta-analysis suggests Gabapentin has best evidence for vasomotor symptom control; but not well tolerated; $50 \%$ patients reported at least one adverse event.

5. Gabapentin is also used for treatment of neuropathic pain, trigeminal neuralagia (off license) and in postherpetic neuralgia where amitriptyline has failed to give adequate control

6. NB: Gabapentin (and pregabalin) classified as a class C controlled substance from April 2019, due to substance misuse concerns.

4. Clonidine: Alpha Adrenergic Receptor Agonist / Anti Hypertensives.

1. Helps to reduce hot flushes, although evidence base contradictory

2. Clinical trial daily dose range: 50 micrograms - 150micrograms orally; one trial with transdermal system demonstrated better symptom control than reported with oral route

3. Clonidine 50 micrograms twice daily for 2 weeks; then increase if necessary to 75 micrograms twice daily; licensed in UK for menopausal symptom control

4. Side effects, including difficulty sleeping, in up-to half of users

5. Prescription should not be stopped abruptly, as this could cause rebound hypertension 
5. Progestogens: Hormones used in gynaecology

1. Unlicensed for menopause vasomotor symptom control; lower doses then those used for breast cancer treatment eg. Norethisterone 1-10 mg daily; Megestrol Acetate $20 \mathrm{mg}$ to $40 \mathrm{mg}$ daily .

2. NICE NG101 states that progestogens should not to be prescribed in breast cancer patients to help with menopausal vasomotor symptom control.

3. Progestogens for vasomotor symptom control could be considered in patients with non hormonal sensitive tumours, after a full risk benefit discussion. Caution: With tumour studies with progesterone receptor sensitivity, decision to use progestogens for vasomotor symptom control must be agreed with patient's oncologist and based on level of progestogen sensitivity (strong to weak)

4. Licensed as breast cancer treatments in high doses; role of progestogens in breast cancer has declined.

NB: Doses: Medroxyprogesterone in breast cancer 400 - $1500 \mathrm{mg}$ daily; Megestrol in breast cancer $160 \mathrm{mg}$ daily, in single or divided doses; Norethisterone in breast cancer, $40 \mathrm{mg}$ daily increased to $60 \mathrm{mg}$ daily if required

* Tamoxifen - Interaction with SSRI and SNRIs

The efficacy of tamoxifen therapy (a selective oestrogen receptor modulator) for the treatment of breast cancer varies widely among individuals. Selective serotonin reuptake inhibitor antidepressants are often prescribed to treat hot flashes in women who may or may not be co-prescribed tamoxifen (1).

Plasma concentrations of the active tamoxifen metabolite, endoxifen, are associated with the cytochrome P450 (CYP) 2D6 genotype. Endoxifen is thought to play a role in providing protection against breast cancer recurrence. $(2,3,4)$

Some SSRls are known to inhibit cytochrome P450 (CYP) 2D6, an enzyme that is important for the metabolism of many drugs, including tamoxifen (2). Venlafaxine, an SNRI, is thought to be a less potent inhibitor as compared to the SSRIs. It has also been noted that the magnitude of decrease in endoxifen concentration was greater in women with the wild-type CYP2D6 genotype than in those with a variant genotype $(P=0.03)(5)$

Interactions between CYP2D6 polymorphisms and co-administered antidepressants and other drugs that are CYP2D6 inhibitors may be associated with altered tamoxifen activity. Jin $Y$ and colleagues demonstrated that the plasma endoxifen concentration was slightly reduced in women taking venlafaxine, a weak inhibitor of CYP2D6, but reduced substantially in subjects who took paroxetine (a potent inhibitor of CYP2D6) (2).

Binkhorst $L$ et al noted that paroxetine and fluoxetine are associated with the greatest ability to inhibit CYP2D6 activity and significant, up to $66 \%$, reduced endoxifen plasma concentrations were observed in tamoxifen-treated patients receiving these drugs concomitantly (6). 


\section{W/HS}

London North West University Healthcare

A quality care initiative program (7) noted that some studies raised concerns about interactions between tamoxifen and antidepressants that inhibit cytochrome P450 2D6 (CYP2D6), reducing the conversion of tamoxifen to the active metabolite endoxifen and, thereby, increasing the risks of recurrence and mortality. However, meta-analyses have suggested that the reductions in endoxifen do not translate into increased breast cancer recurrence rates or mortality rates, possibly because the therapeutic dosing of tamoxifen fully saturates the oestrogen receptor.

Existing recommendations (8) are conservative, cautioning avoidance of potent CYP2D6 inhibitors (e.g., paroxetine, fluoxetine, high-dose sertraline, bupropion) with tamoxifen. Although these antidepressants are not recommended as first-line agents, clinical judgement can be exercised in their use with patients for whom safer alternatives are not an option, after discussion with the treating oncologist has occurred and informed consent been obtained. More potent CYP2D6 inhibitors may be safer to use in postmenopausal women or women with a known extensive metabolizer CYP2D6 genotype. When possible, it is prudent to prefer antidepressants with low CYP2D6 inhibition (e.g., citalopram/escitalopram, venlafaxine/desvenlafaxine, or mirtazapine) as first-line agents.

Recent critical appraisal of the literature has provided evidence for the value of comprehensive CYP2D6 genotyping panels in guiding treatment decisions for nonmetastatic ER-positive breast cancer patients. Based on this information, it is recommended that alternatives to standard tamoxifen treatments are considered in CYP2D6 poor or intermediate metabolizers $(9,10)$. NB: Currently the Trust does not have access to genotyping services

Bottom line: When prescribing an SSRI or SNRI, due consideration needs to be given to this interaction, which may result in lowered tamoxifen efficacy in breast cancer patients.

1 Nelson H, Vesco K, Haney E, Fu R, Nedrow A, Miller J, Nicolaidis C, Walker M, Humphrey L. Nonohormonal therapies for menopausal hot flashes: systematic review and metaanalysis. JAMA 2006; 295 (17): 2057-2071

2 Yan Jin, Zeruesenay Desta, Vered Stearns, Bryan Ward, et al. CYP2D6 Genotype, Antidepressant Use, and Tamoxifen Metabolism During Adjuvant Breast Cancer Treatment. J Natl Cancer Inst 2005;97:30-9

${ }^{3} \mathrm{Wu}$ X, Hawse JR, Subramaniam M, et al. The tamoxifen metabolite, endoxifen, is a potent antiestrogen that targets estrogen receptor alpha for degradation in breast cancer cells. Cancer Res. 2009 Mar 1;69(5):1722-7.

${ }^{4} \mathrm{M}$ Goetz, C Erlichman, C Loprinzi. Pharmacology of Endocrine Manipulation. Chapter 27; pg 557. In Cancer: Principles and Practice of Oncology. 8th Edition. Devita, Hellman and Rosenberg. 2007

${ }^{5}$ Huber-Wechselberger A.E.,Niedetzky P.,Aigner I.,Haschke-Becher E. Impact of CYP2D6 polymorphism on Tamoxifen therapy: Where are we? Wiener Medizinische Wochenschrift May 2012. 162 (11-12): 252-261

6 Binkhorst L.,Mathijssen R.H.J.,Van Herk-Sukel M.P.P.,Bannink M.,Jager A.,Wiemer E.A.C., Van Gelder T. Unjustified prescribing of CYP2D6 inhibiting SSRIs in women treated with tamoxifen. Breast Cancer Research and Treatment June 2013.139(3):923-929 

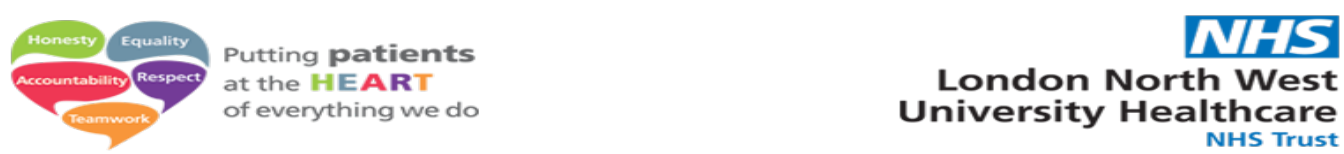

${ }^{7}$ A Quality Initiative of the Program in Evidence-Based Care (PEBC), Cancer Care Ontario (CCO) guidance https://www.cancercare.on.ca/common/pages/UserFile.aspx?fileld=340750 Report Date: May 11, 2015

${ }^{8}$ NICE guidelines [CG101]. Early and locally advanced breast cancer: diagnosis and management. Published July 2018.

${ }^{9}$ Dean L In: Pratt V, McLeod H, Rubinstein W, Dean L, Kattman B, Malheiro A, Editors. Tamoxifen Therapy and CYP2D6 Genotype. Medical Genetics Summaries [Internet]. Bethesda (MD): National Center for Biotechnology Information (US); 2012-.2014 Oct 7 [updated 2016 May 3].

10 Drögemöller BI, Wright GEB, Shih J, et al for the CPNDS Clinical Recommendations Group. CYP2D6 as a treatment decision aid for ER-positive non-metastatic breast cancer patients: a systematic review with accompanying clinical practice guidelines. Breast Cancer Res Treat. 2018 Nov 8. doi: 10.1007/s10549-018-5027-0. [Epub ahead of print]

\section{Weaning off HRT in breast cancer patients}

\section{For postmenopausal patients to be prescribed Aromatase Inhibitors}

1. Stop HRT, including local ERT

- NICE NG101 2018 states that HRT may, in exceptional circumstances, be given to women with early stage cancer with severe menopausal symptoms, as long as the woman has been fully informed about the associated risks of HRT.

- May be acceptable clinical decision for patients on Tamoxifen (antioestrogenic activity on breast tissue); not for patients on aromatase inhibitors.

- Tibolone and progestogens are not recommended to treat menopausal symptoms (Drewe 2015; NICE NG101 2018)

2. Counsel patient about breakthrough vasomotor symptoms. Cross refer for ongoing counselling support (breast cancer specialist nurses, menopause unit specialist nurse; menopause unit counsellor)

3. Evidence base for alternative management strategies weak, but can include acupuncture. NICE NG101 2018 states that soy isoflavones, red clover, black cohosh, vitamin $\mathrm{E}$ and magnetic devices are not recommended for treatment of menopausal symptoms

4. For postmenopausal patients, the risk of osteoporosis is higher due to aging and oestrogen deficiency. This risk is further increased in breast cancer patients prescribed aromatase inhibitors. Assess patient for bone sparing therapy (eg. Bisphosphonates) and offer advice on lifestyle interventions

$>$ Bisphosphonates can be used in breast cancer to prevent and treat osteoporosis or skeletal events, or manage osteolytic lesions, bone pain or hypercalcaemia of malignancy. Bisphosphonates are not licensed for preventing recurrence or improving survival in people with early breast cancer, and use for this indication is offlabel (NICE ES15).

5. NICE NG101 2018 / SIGN 2013 recommends that patients with early invasive breast cancer have a baseline DEXA scan if starting adjuvant Aromatase Inhibitor therapy, have treatment induced menopause or are starting ovarian ablation or suppression therapy 


\section{WHS}

London North West University Healthcare

6. Both SIGN 2013 and NICE NG101 (2018) provide recommendations for extended endocrine therapy, ie continuation after initial treatment in women with ER positive invasive breast cancer. -see excerpt from NICE guidance below

Extended endocrine therapy (NICE 1012018 )

1.7.6 Offer extended therapy (total duration of endocrine therapy of more than 5 years) with an aromatase inhibitor for postmenopausal women with ER-positive invasive breast cancer who are at medium or high risk of disease recurrence and who have been taking Tamoxifen for 2 to 5 years.

1.7.7 Consider extended therapy (total duration of endocrine therapy of more than 5 years) with an aromatase inhibitor for postmenopausal women with ER-positive invasive breast cancer who are at low risk of disease recurrence and who have been taking Tamoxifen for 2 to 5 years.

1.7.8 Consider extending the duration of Tamoxifen therapy for longer than 5 years for both premenopausal and postmenopausal women with ER-positive invasive breast cancer.

2. For patients on HRT, with decision to wean off when diagnosed with breast cancer

1. If Aromatase Inhibitors are prescribed, HRT is stopped immediately

- But if time allows, wean patient off her HRT slowly prior to starting Als

2. If Tamoxifen is prescribed, warn patient of its side effects which include vasomotor symptoms such as hot flushes and night sweats.

- Tamoxifen long duration / extended use is linked with increased risk for thrombosis and endometrial cancer; bone density loss in premenopausal women (NICE NG101 2018)

3. Note that Tamoxifen (SERM action) helps with protection of bone mineral density in postmenopausal women (SIGN 2013; NICE NG101 2018).

4. NICE NG101 2018 states that patients with early invasive breast cancer started on Tamoxifen, regardless of pre-treatment menopause status, do not require a baseline DEXA scan

5. Newly diagnosed breast cancer patients can wean themselves off HRT gradually; but those due to have endocrine surgery to wean themselves off at faster pace.

- Check oestrogen and progestogen content of HRT regimen that patient is on, use half the doses for a month and then stop. Contact Pharmacist (Women's Health) on Health Professional Link-line 020 88692937 for advice on HRT regimens that can be used to gradually wean a patient off HRT and for other medication issues.

6. Breast cancer patients with Tamoxifen side effects, seriously affecting their quality of life, can be cross referred for oncologist reassessment, with view to considering alternatives to Tamoxifen for breast cancer recurrence risk reduction (NICE NG101 2018) 


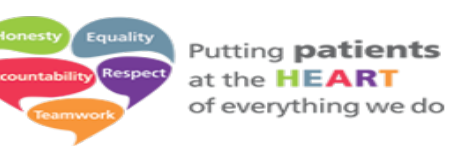

WHS

London North West University Healthcare

7. Use of HRT for women on Tamoxifen, or those with non hormonal sensitive tumours, could be considered after full discussion of risks and benefits with patient. HRT in these circumstances is not a complete contraindication.

8. Evidence base for alternative management strategies weak; but can include acupuncture.

\section{Use of local oestrogen replacement therapy (ERT)}

1. Vaginal oestrogen therapy can be prescribed for local urogenital symptom relief including vaginal dryness, dyspareunia and lower urinary tract infections.

2. Safe usage of vaginal ERT in breast cancer patients has not been studied within RCTs of long duration

3. Clinical consensus suggests that local ERT can be used and is considered safe as long as high levels of systemic absorption are avoided, but decision should be made in co-ordination with the woman's oncologist for women on Als.

4. Consider switching from Aromatase Inhibitors to Tamoxifen in severe cases of vaginal atrophy, before decision re use of local oestrogen replacement therapy

5. For patients with tissue tumour studies suggesting oestrogen receptor negative status, could consider Vagifem (10microgram oestradiol vaginal tablets) or the less potent Ovestin or generic oestriol vaginal creams $(0.1 \%, 0.01 \%$ oestriol respectively). Vagifem licensed for indefinite use, based on patient's symptoms.

6. Estring, a vaginal oestrogen ring can be used for up-to 2 years without resulting in high sustained systemic absorption warranting co-prescribed progestogen for endometrial protection (Estring SPC; but not tested in breast cancer patients)

7. Consider non hormonal vaginal lubricants or moisturisers as the first line choice, eg. Replens (a bio-adhesive vaginal moisturiser), YES, Sylk etc in patients with vaginal symptoms, especially where local ERT is not acceptable as treatment. NB: KY Jelly is a vaginal lubricant that should be avoided as not effective. Can feel gritty, irritate vaginal tissue and patients may find it to be 'messy'.

8. NB: Newer licensed treatments for symptomatic vulvar vaginal atrophy (VVA) but contra-indicated in breast cancer include

a. Ospemifene (SERM, with oestrogen like effect in the vagina, increasing cellular maturation and mucification of vaginal epithelium). Licensed dose 60mg tablet once daily (Senshoi SPC)

- C/l: suspected breast cancer or active breast cancer treatment

- Ospemifene could be used for VVA but only after treatment of breast cancer, including adjuvant therapy, has been completed (SPC July 2018]

- Not on Trust Formulary 
Putting patients at the HEART

of everything we do

\section{WHS}

London North West

University Healthcare
NHS Trust

b. Prasterone; this DHEA product is metabolised into oestrogenic compounds (Intrarosa $6.5 \mathrm{mg}$ pessary; for treatment of vulvar and vaginal atrophy ) .(Intrarosa SPC)

- C/l: known, past or suspected breast cancer (ema.europa.eu)

- Not on Trust Formulary

\section{Alternative strategies}

- to include lifestyle and self care options

\section{Lifestyle management}

- Advice has not been tested within rigorous RCT study designs

- Should include weight reduction or maintenance, smoking cessation, caffeine reduction, stress management, both weight bearing and toning exercise, environmental control.

\section{Counselling support}

- May be dealing with younger patient struggling with sexual dysfunction and body image (Finch et al 2011)

- Important to consider holistic management plan individually tailored to patient need.

- Offer patient personalised, culturally aware, support

- Address realistic expectations

- Include options for psychotherapy and psychosexual therapy (Andersen BL et al; Stanton AL et al.)

- MENOS1 (2012) RCT ( $n=96$ ) reported reductions in problem rating at 9 weeks (less depressed mood, fewer sleep problems, less anxiety) and 26 weeks (less depressed mood, fewer sleep problems, less bodily pain) comparing CBT with usual care.

- NICE NG23 2015 recommends CBT as an effective option for low mood associated with menopause

\section{Alternative therapies}

- Examples cited in the literature include reflexology, massage, acupuncture (weak evidence base; survivors of breast cancer who have had axillary surgery should avoid acupuncture to the particular arm), aromatherapy (some caution), hypnotherapy, homeopathy

- Anecdotal evidence but no good robust RCT research

- Advice patient to see a qualified, regulated practitioner 


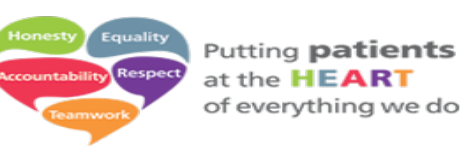

WHS

London North West University Healthcare

\section{Herbal treatments and food supplements}

- Should not be recommended for use by breast cancer patients on Aromatase Inhibitors

- Caution with use of these supplements in breast cancer patients as all have some oestrogenic activity and safety data for use in these patient groups is not available

- May be safe in breast cancer patients with Stage 1 and 2 receptor negative status

- 3 year RCT study in 401 women with family history of breast cancer, designed to study use of Novogen Red Clover isoflavones (40mg per tablet), reported neutral effect on mammographic breast density (Powles $\mathrm{T}$ et al. Menopause Int. 2008)

- Phytoestrogens can form a large part of dietary intake in certain ethnic groups. These patients can be advised to continue with what may be considered to be normal levels of dietary intake, but it is not known if it is safe for breast cancer patients to take supplements of higher doses.

- NICE NG101 2018 states that soy isoflavones, red clover, black cohosh, vitamin $E$ and magnetic devices are not recommended for treatment of menopausal symptoms

- $\quad$ NICE NG23 2015 suggests that women are advised that the quality, purity and constituents of complementary therapies may be unknown

- NICE NG101 2015 recommends that women with a history of or at high risk of breast cancer should be advised that there is some evidence that St John's Wort may be of benefit for vasomotor symptom control, but

o there is uncertainty about appropriate doses, persistence of effect, variation in the nature and potency of preparations

o there are some potential serious drug - drug interactions (including tamoxifen, anticoagulants, anticonvulsants and immunosuppressants).

\section{BRCA testing and induced menopause}

With the wider use of genetic testing for BRCA1 and BRCA2 gene variants, women are increasingly seeking advice in relation to the use of hormone replacement therapy (HRT) following Risk Reducing Bilateral Salpingo-oophorectomy (RRBSO). In this group of women, RRBSO is usually performed around the age of 40 years. Some women will also undergo risk reducing bilateral mastectomy, others will opt for annual breast surveillance or medical intervention, such as Tamoxifen.

All women who undergo RRBSO will face the effects of surgical menopause, both short term which may include vasomotor symptoms, sleep disturbance and sexual dysfunction as well as potential long term risks of osteoporosis, coronary heart disease and cognitive decline associated with premature menopause $(1,2)$. In addition, they may experience psychological issues surrounding facing the menopause at a young age (3) 
W/HS

London North West University Healthcare
NHS Trust

Guidance from NICE covers this in two ways. Guidance NG 164 (Familial breast cancer: classification, care and managing breast cancer and related risks in people with a family history of breast cancer) explains that women should be given information about the effects of surgical menopause prior to surgery and strategies discussed to reduce symptoms and reduce risk of long term health effects. In the absence of contraindications, women who do not have personal history of breast cancer are advised to use HRT until the average age of menopause (CG 164, 1.71.61). Guidance NG 23 (Menopause diagnosis and management) advises that women about to undergo surgical menopause as a result of cancer or for risk reducing purposes should be referred to a health professional with expertise in menopause (1.3.6)

NB: NICE NG 101(2018) also recommends genetic testing for BRCA1 and BRCA2 variants for women under 50 years with triple-negative breast cancer, including those with no family history of breast or ovarian cancer. The Pan Thames Clinical Genetic Services offer genetic testing for BRCA1 and BRCA2 variants for women with triple negative breast cancer diagnosed under the age of 60 years, as studies have shown that there is at least a $10 \%$ chance of identifying a BRCA1 or BRCA2 variant in this patient subgroup.

\section{LNWUHT Recommendations}

For women diagnosed with BRCA1 or BRCA2 variant, there should be close multidisciplinary working with breast team, genetics team and menopause team for management of women undergoing RRBSO.

- Referral to the Menopause Clinic prior to surgery useful in order to provide women with information in advance of surgery and to enable them to make an informed decision about the use of HRT if indicated.

- Evidence base for routine recommendation for TAH and BSO is not robust.

- TAH option may be considered on individualised patient basis, for another indication, with risk benefit evaluation.

- If appropriate, oncology team to consider endometrial sampling with discussion of Mirena option as the progestogenic component of HRT regimen, at time of RRBSO.

\section{$\underline{\text { References }}$}

1. Finch, A., Metcalfe, K.A., Chiang, J.K., Elit, L., McLaughlin, J., Springate, C. et al, The impact of prophylactic salpingo-oophorectomy on menopausal symptoms and sexual function in women who carry a BRCA mutation. Gynecol. Oncol. 2011;121:163-168.

2. Harmsen, Marline G. et al. How medical choices influence quality of life of women carrying a BRCA mutation Critical Reviews in Oncology Hematology , 2015; 96 , Issue 3, 555 - 568

3. Stan D, Shuster L, Wick M. Swanson CL. et al. Challenging and Complex Decisions in the Management of the BRCA Mutation Carrier Journal of Women's Health. October 2013, Vol. 22, No. 10: 825-83

4. NICE Guidance NG 164 Familial breast cancer: classification, care and managing breast cancer and related risks in people with a family history of breast cancer. Published 2013. Updated March 2017.

5. NICE Guidance NG 23. Menopause diagnosis and management. Published 2015 


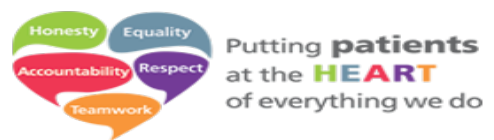

6. NICE guidelines [CG101]. Early and locally advanced breast cancer: diagnosis and management. Published July 2018.

\section{Bibliography:}

Andersen BL, Farrar WB, Golden-Kreutz DM et al. Psychological, Behavioural, and Immune Changes After a Psychological Intervention: A Clinical Trial @ September 2004 by American Society of Clinical Oncology

Baber R, Hickey M, Kwik M. Therapy for menopause symptoms during and after treatment for breast cancer: safety considerations. Drug Safety 2005;28(12):1085-1100

Bergkvist L. Chapter on: Hormone Replacement Therapy and breast cancer mortality. Clinical Management of the Menopause. McGraw-Hill, 1996

Boekhout A.H., Vincent A.D.,Dalesio OB, et al. Management of hot flashes in patients who have breast cancer with venlafaxine and clonidine: A randomized, double-blind, placebo-controlled trial. Journal of Clinical Oncology; 2011; 29: 3862-3868

Cobin RH, Goodman NF; AACE Reproductive Endocrinology Scientific Committee. American Association of Clinical Endocrinologists and American College of Endocrinology Position Statement on Menopause - 2017 Update. Endocr Pract. 2017 Jul;23(7):869-880. doi: 10.4158/EP171828.PS. https://www.ncbi.nlm.nih.gov/pubmed/28703650

Committee Opinion No 659. The use of vaginal estrogen in women with a history of estrogendependent breast cancer. American College of Obstetricians and Gynaecologists. Obstet Gynecol 2016,127:e93-6

Drewe J, Bucher KA, Zahner C. A systematic review of non-hormonal treatments of vasomotor symptoms in climacteric and cancer patients. Springerplus. 2015;4: 65. Published online 2015 Feb 10. doi: 10.1186/s40064-015-0808-y

Drögemöller BI, Wright GEB, Shih J, et al for the CPNDS Clinical Recommendations Group. CYP2D6 as a treatment decision aid for ER-positive non-metastatic breast cancer patients: a systematic review with accompanying clinical practice guidelines. Breast Cancer Res Treat. 2018 Nov 8. doi:

10.1007/s10549-018-5027-0. [Epub ahead of print]

Finch, A., Metcalfe, K.A., Chiang, J.K., et al, The impact of prophylactic salpingo ophorectomy on menopausal symptoms and sexual function in women who carry a BRCA mutation. Gynecol. Oncol. 2011;121:163-168.

Gabapentin 300mgm SPC. Updated January 2018. https://www.medicines.org.uk/emc/product/4636/smpc Goetz M, Erlichman C, Loprinzi C. Pharmacology of Endocrine Manipulation. Chapter 27; pg 557. In Cancer: Principles and Practice of Oncology. 8th Edition. Devita, Hellman and Rosenberg. 2007

Gordhandas S, Norquist BM, Pennington KP, et al. Hormone replacement therapy after risk reducing salpingo-oophorectomy in patients with BRCA1 or BRCA2 mutations; a systematic review of risks and benefits. Gynecol Oncol. 2019 Jan 17. pii: S0090-8258(18)31514-2. doi:

10.1016/j.ygyno.2018.12.014. [Epub ahead of print] 


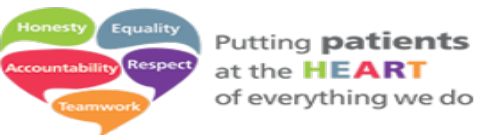

W/HS

London North West University Healthcare

Guha N, Kwan ML, Quesenberry CP Jr, et al. Soy isoflavones and risk of cancer recurrence in a cohort of breast cancer survivors: the Life After Cancer Epidemiology study. Breast Cancer Res Treat. 2009 Feb 17. [Epub ahead of print]

Hickey M, Davis SR, Sturdee D. Treatment of menopausal symptoms: what shall we do now? Lancet 2005;366:409-21

Hickey M, Saunders CM, Stuckey BG. Management of menopause symptoms in patients with breast cancer: an evidence based approach. Lancet Oncol 2005;6(9):687-695.

Hickey M, Saunders C, Partridge A, et al. Practical clinical guidelines for assessing and managing menopausal symptoms after breast cancer. Annals of Oncology 2008;19:1669-1680

Holmberg L, Iversen OE, Rudenstam CM, et al. HABITS Study Group. Increased risk of recurrence after hormone replacement therapy in breast cancer survivors. J Natl Cancer Inst.2008 Apr 2;100(7):475-82.

Intrarosa - Summary of the European Public Assessment Report (EPAR). https://www.ema.europa.eu/en/medicines/human/EPAR/intrarosa\#overview-section

Intrarosa SPC. 4th Sept., 2019.

https://www.medicines.org.uk/emc/product/9986/smpc\#CONTRAINDICATIONS

Jin Y, Desta Z, et al. CYP2D6 Genotype, Antidepressant use, and Tamoxifen Metabolism during Adjuvant Breast Cancer Treatment. J Natl Cancer Inst 2005;97:30-39

Kassab S, Cummings M, Berkovitz S, van Haselen R, Fisher P. Homeopathic medicines for adverse effects of cancer treatments. Cochrane Database of Systematic Reviews 2009, Issue 2. Art. No.: CD004845. DOI: 10.1002/14651858.CD004845.pub2

Kelsberg G, Maragh L, Safranek S. Clinical Inquiry: Which nonhormonal treatments are effective for hot flashes? J Fam Pract. 2016;65(5):E1-3.

Kenemans P, Bundred NJ, Foidart JM, et al. LIBERATE Study Group. Safety and efficacy of tibolone in breast-cancer patients with vasomotor symptoms: a double-blind, randomised, non-inferiority trial. Lancet Oncol. 2009 Feb;10(2):135-46.

Kuchenbaecker KB, Hopper JL Barnes DR et al. . Risks of Breast, Ovarian, and Contralateral Breast Cancer for BRCA1 and BRCA2 Mutation Carriers. JAMA. 2017 Jun 20;317(23):2402-2416. doi: 10.1001/jama.2017.7112.

Mann E, Smith MJ, Hellier J, et al. Cognitive behavioural treatment for women who have menopausal symptoms after breast cancer treatment (MENOS 1): a randomised controlled trial. Lancet Oncology 2012; 13 (3): 309-318

Li L, Xu L, Wu J,et al. Comparative efficacy of non hormonal drugs on menopausal hot flashes. Eur J Clin Pharmacol. 2016;72(9):1051-8. doi: 10.1007/s00228-016-2090-5. Epub 2016 Jul 24.

Morrison EE, Sandilands EA, Webb DJ. Gabapentin and pregabalin: do the benefits outweigh the harms? J R Coll Physicians Edinb. 2017;47(4):310-313. doi: 10.4997/JRCPE.2017.402.

Morrow P.K.H.,Mattair D.N.,Hortobagyi G.N .Hot flashes: A review of pathophysiology and treatment modalities. Oncologist; 2011; 16: 11: 1658-1664 


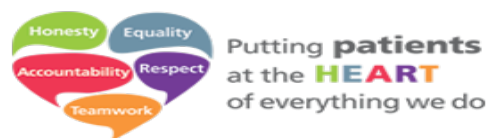

\section{NHS \\ London North West University Healthcare}

Nelson H, Vesco K, Haney E, et al. Nonhormonal therapies for menopausal hot flashes: systematic review and meta-analysis. JAMA 2006;295(17):2057-2071

NICE guideline CG80. Surveillance report November 2015. Early and locally advanced breast cancer (2009) CG80 surveillance-review-decision-november-2015-2178657613.pdf NICE clinical guideline [CG81]. Advanced breast cancer: diagnosis and treatment. Published date: February 2009 Last updated: August 2017 https://www.nice.org.uk/guidance/cg81

NICE guidelines [NG101]. Early and locally advanced breast cancer: diagnosis and management. Published July 2018. https://www.nice.org.uk/guidance/ng101/chapter/Finding-more-information-andresources

NICE guidelines [CG164]. Familial breast cancer: classification, care and managing breast cancer and related risks in people with a family history of breast cancer. Published June 2013. Last updated March 2017. https://www.nice.org.uk/guidance/cg164

NICE guidelines [NG23]. Menopause: diagnosis and management. Published November 2015. https://www.nice.org.uk/guidance/NG23

NICE Evidence Summary ES15. Early breast cancer (preventing recurrence and improving survival): adjuvant bisphosphonates. Published July 2017.

Panay N \& Rees M for the Scientific Advisory Committee Opinion Paper 6. Alternatives to HRT for Management of Symptoms of the Menopause. RCOG. $2^{\text {nd }}$ Edition 2010

Pop A, Tanna N, Pitkin J. Breast cancer patient case study - prescribing of Gabapentin for vasomotor symptom control and supporting patient compliance / concordance. EMAS conference $17^{\text {th }}-20^{\text {th }}$ May, 2009.

Powles TJ, Howell A, Evans DG et al. Menopause Int. 2008;14(1):6-12

Rada G, Capurro D, Pantoja T, Corbalán J, Moreno G, Letelier LM, Vera C. Non-hormonal interventions for hot flushes in women with a history of breast cancer. Cochrane Database of Systematic Reviews 2010, Issue 9. Art. No.: CD004923. DOI: 10.1002/14651858.CD004923.pub2. Assessed as up to date: August 22, 2008

Roberts H. Managing the Menopause. BMJ 2007;334:736-741

Rock CL, Flatt SW, Laughlin GA, et al. Women's Healthy Eating and Living Study Group. Reproductive steroid hormones and recurrence-free survival in women with a history of breast cancer. Cancer Epidemiol Biomarkers Prev. 2008 Mar;17(3):614-20.

Savard J, Simard S, Ivers H, Morin CM. Randomized study on the efficacy of cognitive-behavioral therapy for insomnia secondary to breast cancer, part I: Sleep and psychological effects. J Clin Oncol. 2005 Sep 1;23(25):6083-96.

Scottish Intercollegiate Guidelines Network (SIGN). Treatment of primary breast cancer. Edinburgh: SIGN; 2013. (SIGN publication no. 134). [September 2013].

https://www.sign.ac.uk/assets/sign134.pdf

Senshio SPC. 23rd July 2018.

https://www.medicines.org.uk/emc/product/9417/smpc\#PRODUCTINFO 


\section{NHS}

London North West University Healthcare

Stanton AL, Danoff-Burg S, Cameron CL et al. Emotionally expressive coping predicts psychological and physical adjustment to breast cancer. Journal of Consulting and Clinical Psychology, Vol 68(5), Oct 2000, 875-882.

Stubbs C, Mattingly L, Crawford SA, et al. Do SSRIs and SNRIs reduce the frequency and/or severity of hot flashes in menopausal women. J Okla State Med Assoc. 2017;110(5):272-274.

Sun Z, Hao Y, Zhang M. Efficacy and safety of desvenlafaxine treatment for hot flashes associated with menopause: a meta-analysis of randomized controlled trials. Gynecologic and Obstetric Investigation 2013; 75(4): 255-262

Tice JA, Grady D. Alternatives to Estrogen for Treatment of Hot Flashes. JAMA 2006;295(17):20762078.

Toi M, Yamashiro H, Tsuji W. Risk reduction of distant metastasis in hormone sensitive postmenopausal breast cancer. Breast Cancer. 2009 Mar 4. [Epub ahead of print]

Velentzis LS, Woodside JV, Cantwell MM, et al. Do phytoestrogens reduce the risk of breast cancer and breast cancer recurrence? What clinicians need to know. Eur J Cancer. 2008 Sep;44(13):1799806.

Woyka J and Tanna N. Consensus statement for non-estrogen-based treatments for menopausal symptoms. Post Reproductive Health 2014; 20(2): 76- 79

Woyka J. Consensus statement for non-hormonal-based treatments for menopausal symptoms. Post Reprod Health. 2017;23(2):71-75. doi: 10.1177/2053369117711646.

Wu X, Hawse JR, Subramaniam M, et al. The tamoxifen metabolite, endoxifen, is a potent antiestrogen that targets estrogen receptor alpha for degradation in breast cancer cells. Cancer Res. 2009 Mar 1;69(5):1722-7.

\section{Acknowledgement:}

Medicines Information, LNWUHT. For supporting review of use of Tamoxifen with SSRIs and SNRIs.

\begin{tabular}{|l|l|}
\hline Authors & Nuttan Tanna, Luca Fusi, Naim Kadoglou \\
\hline Date of writing & $2009 ;$ reviewed 2012; 2015; 2019 \\
\hline Date reviewed & June 2019 \\
\hline Date approved by D\&T Group & 19 September 2019 \\
\hline Date of next review & 19 September 2021 \\
\hline
\end{tabular}

The LNWUHT menopause team, breast unit team and genetics team: Jane Woyka, GP Associate Specialist, Menopause Team

Kathy Abernethy, Senior Nurse Specialist \& Co-lead, Menopause Team

Robert Reichert, Consultant Breast Surgeon

Jason Lee, Consultant Breast Surgeon

Sabina Rashid, Consultant Breast Surgeon

Mia Morgan, Consultant Radiologist

Angela Fanshaw, Breast Registrar

Hannah Ford, Breast Care Clinical Nurse Specialist

Marigilka Colquhoun, Breast Speciality Doctor

Dani Singer, Counsellor \& Clinical Psychotherapist, Menopause Team

Demetra Georgiou, Principal Genetic Counsellor South East Thames Regional Genetics Service, Honorary Genetic Counsellor North West Thames Regional Genetics Service

Dr Angela Brady, Consultant Clinical Geneticist and Cancer Lead North West Thames Regional Genetics Service 